\title{
AC 2009-1801: ENGINEERING COLLABORATIONS WITH LIBERAL ARTS
}

Monica Anderson, University of Alabama

Beth Todd, University of Alabama

Susan Burkett, University of Alabama

Garry Warren, University of Alabama

Marcus Brown, University of Alabama

David Cordes, University of Alabama 


\title{
Engineering Collaborations with Liberal Arts
}

\begin{abstract}
Meaningful engagement of engineering students with the liberal arts presents a unique set of challenges. This paper outlines a series of activities designed to foster collaborations between engineering and the liberal arts. Over the last few years, we have been engaged in a number of activities on campus where students and faculty from engineering work side-by-side with students and faculty from the theatre, dance, telecommunications \& film, music, and other disciplines. In this paper we describe a set of cooperative activities on our campus, explore the benefits and lessons learned from these activities, examine the resources and relationships required for them to succeed, and provide a model for the institutionalization of these collaborative ventures.
\end{abstract}

\section{Introduction}

As part of an institution-wide initiative, our College of Engineering has recently seen an increased emphasis on interactions and collaborations with other programs and colleges at the university. The institution is actively promoting a Creative Campus initiative that focuses on the engagement of students in a wide range of activities. Creative Campus is an organization for students, faculty and staff to support the arts and creative activity on campus.

These activities are similar to other initiatives and ventures that are taking place across the country. Several institutions ${ }^{1,2}$ have investigated formal linkages between an engineering degree and the liberal arts, developing a Bachelor of Arts in Engineering. Other initiatives provide course experiences that introduce the field of engineering to non-majors ${ }^{3,4,5}$. Still other efforts look at incorporating fundamental issues of other disciplines, such as leadership, into the engineering curriculum ${ }^{6,7}$. Finally, several examples exist where interdisciplinary courses are established that bridge engineering with other disciplines ${ }^{8,9,10}$.

The concept of a tighter integration between engineering and the humanities $\&$ fine arts has been around for many years ${ }^{11}$. A properly educated engineer should have an understanding of the social sciences and humanities. However, such a viewpoint is not without its critics ${ }^{12}$. A curriculum that embeds this linkage into specific course content is one approach ${ }^{13}$, but such a model is difficult to implement and has not received much national attention. While not everyone agrees that engineering faculty are resistant to this proposed change ${ }^{14}$, there has been little movement nationally with respect to true curricula change.

\section{Collaborative Ventures}

In this section we will briefly overview four collaborations that have taken place on our campus over the past two years. Each of these collaborations was developed independently through conversations between faculty and administrators in the two colleges. The length of engagement for each of these collaborations was approximately one semester in length; two involved upperdivision engineering students and two involved freshman engineering students. 
Collaboration \#1: upper-division engineering students and the dance program. This collaboration was led by a faculty member in computer science and the director of the university's dance program. Working with dance and engineering students, the project tracked the movement of the dancers on the stage for a performance entitled Frequency that represented the finale of the Repertory Dance Theatre's spring recital. "This is probably the most innovative concert we have ever done" was the quote of the director of our dance program. The basic theme of "aliens among us" was realized when alien dancers distorted the signals on radios and televisions as they came in close contact with them. "We created a workshop this semester so students can experiment using technology and engineering in dance performances. The students have displayed incredible knowledge, creativity and professionalism in their approach to using technology" according to the computer science faculty member involved in the project.

Collaboration \#2: upper-division engineering students and the theatre program. The Spring 2009 Theatre production is Henry $V$ by William Shakespeare. A group of senior engineering students are working with the production cast to implement the special effects. Specifically, there are a number of battle scenes that needed to be rendered realistically. This includes sight, sound, smell and feel. The students are currently collaborating on a venture that will fully immerse the audience in the battlefield.

Collaboration \#3: first-year engineering students and the music program. This project was initiated by the music department as part of its annual fund-raising activity. The basic premise was to construct a working light fixture from a musical instrument. Students brainstormed ideas that used the inherent qualities of the various instruments to control the lighting and attention was focused on the artistic component of the construction. The instruments included a saxophone, clarinet, bassoon, piccolo, trumpet, mellophone and trombone. Students were given a budget ( $\$ 60$ per instrument) and the resulting lamps were auctioned at the fundraiser. The faculty members involved were impressed with the creativity exhibited by the students.

Collaboration \#4: first-year engineering students and the telecommunications \& film program. Students at our institution take a two semesters of freshman engineering. These courses focus on ensuring the students have the fundamentals that they need to successfully complete the sophomore year engineering science courses. In addition, teaming and other issues are addressed. All first-semester students give two presentations to their class; the first is a oneminute presentation and the second is a one-minute video. The one-minute video can be on "why they are majoring in engineering" or "a day in my life" or "why I picked this university." An introductory film production class selected the top ten videos and converted them into professional productions that can be used by the college for recruiting purposes.

\section{Observations and Lessons Learned}

When we discuss these activities with other faculty members, both on and off campus, we routinely get asked two regarding this venture. First, do engineering students learn anything about the liberal arts from these experiences? Second, does this help students develop an appreciation for the other discipline or does it harden attitudes against the other field? 
Looking at the first question, we believe that the students immersed in these activities gain as much from these course experiences as they would from a traditional "liberal arts service course for non-majors." There is a difference in their education, however. Rather than covering a broad set of material at a relatively shallow level, these students are focused on a single topic and learn the issue at a much deeper level. Students must understand the problem domain in order to effectively incorporate their engineering designs, and students also interact regularly with students from the liberal arts - the ones performing the recital or enacting the play.

With respect to the second question, we were honestly surprised at the appreciation that the two groups of students developed for each other. Many of the students in engineering who were involved in these projects had an interest in the field. However, after working with students in dance or theatre for several months, the engineering students realized that their interest and abilities in these areas was dwarfed by those students majoring in the field. They came away from the project with a new respect for the talent, passion and dedication of the performers. Likewise, students in the liberal arts realized that implementing some of their ideas was not a trivial task, and that significant time and energy was required to design a quality solution to what appeared to be a relatively simple request (such as TVs flickering when a person gets close or coordinating the flash, report, and shock of a cannon shell's explosion).

Finally, we acknowledge that we have not yet done any formal assessment of these activities. We have talked with students and faculty afterwards. All those involved feel that it was a valuable learning experience that has contributed uniquely to the students' educations. However, we do not have any direct measures to demonstrate the success of this venture.

\section{Institutionalization}

Numerous discussions have taken place on campus regarding how to best institutionalize these endeavors. All participants, students and faculty, agree that we must recognize the effort involved in these projects in order for this concept to grow and thrive in future years. Students and faculty also agree that course credit is the best method for recognition, as it moves the students closer to graduation and course instruction is a recognized part of a faculty member's workload.

Initially, our thought was to provide credit within the engineering portion of a student's curriculum for these activities. However, resistance to this approach was seen from both engineering and the liberal arts. Within the college of engineering, there were faculty that felt this activity was not appropriate for "professional" credit, and students should instead be taking senior-level courses in their respective disciplines. Within the liberal arts, students had no way of applying an engineering course towards their degree plan; it was often an additional course that was not required of them.

However, all students at our institution are required to complete a common core curriculum. This core curriculum includes multiple courses in the humanities and fine arts. Given this, we are in the process of institutionalizing a limited enrollment course that engineering students could take for humanities and fine arts credit - it would count towards the core curriculum for engineering students. It would also obviously plug into the curriculum for students in these 
fields who are working side-by-side with our engineering students on these projects. Enrollment would be by invitation only; students would have to apply for admission to these courses.

\section{Summary}

The paper has illustrated several examples of engineering collaborations with the liberal arts at our institution. While no formal assessment has been done on these experiences, anecdotal evidence from those involved indicates that this collaboration is worth continuing. The paper presents a model for the institutionalization of this framework, providing a vehicle that gives students and faculty the credit required to sustain this initiative in the long term.

\section{Bibliography}

1. A BA Engineering and Liberal Studies Degree at a Polytechnic Institution, Dan Walsh and Stacey Breitenback, AC 2007-1393, ASEE 2007, June 24-27, 2007, Honolulu, Hawaii.

2. The Bachelor of Arts in Engineering: A Paradigm for Bridging the Liberal Arts and Engineering, Sharon Jones, AC 2008-85, ASEE 2008, June 22-25, 2008, Pittsburgh, PA.

3. Introducing Engineering and Technology to Non-Majors: Benefits, Challenges, and Opportunities in Offering a Technological Literacy Course, John Blake, AC 2007-2594, ASEE 2007, June 24-27, 2007, Honolulu, Hawaii.

4. Teaching Engineering to the disinterested: A case study in teaching engineering principles to non-engineering majors, Gerald Himes, Jakob Bruhl, Joseph Hanus, AC 2008-1642, ASEE 2008, June 22-25, 2008, Pittsburgh, PA.

5. Technology in Context: integrating technological "literacy" with science requirements for non-majors, Kathryn Neeley, W. Bernard Carlson, Sarah Pfatteicher, Bruce Seely, Douglass Klein, Ronal Miller, AC 2008-1732, ASEE 2008, June 22-25, 2008, Pittsburgh, PA.

6. Migration from a leadership honors program to an engineering leadership minor, Gregory Tonkay and E. Zimmers, AC 2007-2283, ASEE 2007, June 24-27, 2007, Honolulu, Hawaii.

7. Building a new kind of engineering degree at James Madison University, Ronald Kander, AC 2008-416, ASEE 2008, June 22-25, 2008, Pittsburgh, PA.

8. First Year Engineering Design: Incorporating Leadership Development into Real Project Experiences, Kevin Sutterer, James Hanson and John Aidoo, AC 2007-2497, ASEE 2007, June 24-27, 2007, Honolulu, Hawaii.

9. Evolution of an Interdisciplinary Sophomore Design Course at the University of Hartford, David Pines and Hisham Alnajjar, AC 2008-1707, ASEE 2008, June 22-25, 2008, Pittsburgh, PA.

10. Integrated Liberal and Professional Pedagogy: An Interdisciplinary Course, Abdul Kamal and Herb Eskot, AC 2007-1077, ASEE 2007, June 24-27, 2007, Honolulu, Hawaii.

11. Engineering a Liberal Education, Domenico Grasso, ASEE Prism, vol. 12, no. 3 (November 2002), p 76.

12. Opening a New Book, Thomas Grose, ASEE Prism, vol. 13, no. 6 (February 2004), p 20-25.

13. Merging Arts and Science, Robin Tatu, ASEE Prism, vol. 15, no. 7 (March 2006), p 52-53.

14. Engineering, Humanities Integration, W.A. Barrett, ASEE Prism, Vol. 13, no. 9 (Summer 2004), p 10. 